\title{
Experiência Memorável de Turistas em Natal-RN
}

\section{Resumo}

Leandro Tavares Bezerra ${ }^{a}$

A atividade turística possibilita ao indivíduo uma diversidade de experiências, porém, autores como Sun-Tung \& Ritchie (2011) alegam que mais especificações devem ser feitas para descobrir o que exatamente torna certas experiências especiais, espetaculares, adequadas e memoráveis. Partindo desse princípio, esse artigo realizou uma revisão teórica sobre o turismo e as experiências advindas dessa atividade, buscou analisar e ampliar as dimensões da experiência definidas por Pine II \& Gilmore (1999), Oh, Fiore \& Jeoung (2007) e as dimensões estudadas por Pezzi \& Vianna (2015), autores base para o presente estudo. A pesquisa teve como objetivo compreender os motivos que levam os turistas a considerarem uma experiência de viagem memorável. Para isso foi realizada a aplicação de questionário com 102 turistas que viajaram para Natal, capital do Rio Grande do Norte, no segundo semestre de 2017. Trata-se de um artigo de natureza exploratória e de abordagem quantitativa. Os dados aqui mencionados foram tratados de forma descritiva. Após análise de correlação feita a partir do software SPSS, os resultados mostraram que os turistas consideraram Natal-RN uma experiência única e memorável, tal fator ocorreu porque obtiveram em comum o desenvolvimento de aprendizagem e conhecimento individual sobre a cidade ou sobre si mesmo durante o seu período de permanência. Sentiram-se atraídos pelo visual da cidade e sua capacidade de entretenimento, fuga e esquecimento de suas rotinas, permitindo vivencias únicas e capazes de fixarem lembranças em suas memórias. Conclui-se que a viagem a Natal-RN superou os aspectos triviais dos turistas e tornou-se uma experiência enaltecedora a ponto de se tornar memorável.

Palavras Chave: Turismo; Experiência; Memória.

\section{Abstract \\ Memorable Experiences of Tourists in Natal-RN}

The tourist activity allows the individual a diversity of experiences, however, authors such as Sun-Tung \& Ritchie, (2011) claim that more specifications must be made to find out what exactly makes certain experiences special, spectacular, appropriate and memorable. Based on this principle, this article carried out a theoretical review on tourism and the experiences arising from this activity, sought to analyze and expand the dimensions of the experience defined by Pine II \& Gilmore (1999), Oh, Fiore \& Jeoung (2007) and the dimensions studied by Pezzi \& Vianna (2015), authors based on the present study. The research aimed to understand the reasons that lead tourists to consider a memorable travel experience. For this purpose, a questionnaire was applied to 102 tourists who traveled to Natal, capital of Rio Grande do Norte, in the second half of 2017. This is an exploratory article with a quantitative approach. The data mentioned here were treated in a descriptive manner. After a correlation analysis made using the SPSS software, the results showed that tourists considered Natal-RN to be a unique and memorable experience, this factor occurred because they had in common the development of individual learning and knowledge about the city or about themselves during the their period of stay. They were attracted by the city's look and its capacity

a. Mestre em Turismo pela Universidade Federal do Rio Grande do Norte, Natal, RN, Brasil. E-mail: thavaresleandro@hotmail.com 
for entertainment, escape and forgetting its routines, allowing for unique experiences capable of fixing memories in their memories. We conclude that the trip to Natal-RN overcame the trivial aspects of tourists and became an exhilarating experience to the point of becoming memorable.

Keywords: Tourism; Experience; Memory.

\section{Resumen}

\section{Experiencia Memorable de Turistas en Natal-RN}

La actividad turística le permite al individuo una diversidad de experiencias, sin embargo, autores como Sun-Tung \& Ritchie (2011) afirman que se deben hacer más especificaciones para descubrir qué hace que ciertas experiencias sean especiales, espectaculares, apropiadas y memorables. Sobre la base de este principio, este artículo realizó una revisión teórica sobre el turismo y las experiencias derivadas de esta actividad, buscó analizar y ampliar las dimensiones de la experiencia definida por Pine II y Gilmore (1999), Oh, Fiore y Jeoung (2007) y las dimensiones estudiadas por Pezzi y Vianna (2015), autores basados en el presente estudio. La investigación tuvo como objetivo comprender las razones que llevan a los turistas a considerar una experiencia de viaje memorable. Para este propósito, se aplicó un cuestionario a 102 turistas que viajaron a Natal-RN, capital de Rio Grande do Norte, en la segunda mitad de 2017. Este es un artículo exploratorio con un enfoque cuantitativo. Los datos mencionados aquí fueron tratados de manera descriptiva. Después de un análisis de correlación realizado con el software SPSS, los resultados mostraron que los turistas consideraban que NatalRN era una experiencia única y memorable, este factor ocurrió porque tenían en común el desarrollo del aprendizaje individual y el conocimiento sobre la ciudad o sobre ellos mismos durante el su período de estancia. Se sintieron atraídos por el aspecto de la ciudad y su capacidad de entretenimiento, escape y olvido de sus rutinas, lo que permitió experiencias únicas capaces de fijar recuerdos en sus recuerdos. Concluimos que el viaje a Natal-RN superó los aspectos triviales de los turistas y se convirtió en una experiencia emocionante hasta el punto de ser memora.

Palabras Clave: Turismo; Experiencia; Memoria.

\section{INTRODUÇÃo}

As experiências proporcionadas por intermédio das atividades turísticas implicam em uma série de reflexões sobre a influência na escolha do destino, e também, na ligação que o turista cria com a localidade visitada. Isso acarretou na necessidade de entender os fatores que ligam turistas e destinos turísticos. Os estudos de Turner (1982; 1986), Krippendorf (1989), Pine II \& Gilmore (1998; 1999; 2000), Li (2000), Mac Cannell (2003), Uriely (2005), Dawsey (2005), Oh, Fiore \& Jeoung (2007), Kim (2009), Sun-Tung \& Ritchie (2011), Chandralal \& Valenzuela (2013; 2015), Pezzi \& Vianna (2015), Bezerra \& Silva (2016), Coelho, Gosling \& Almeida (2018), dentre outros, apresentam reflexões e ajudam a entender as relações construídas e desenvolvidas entre turistas, o local visitado e as experiências vivenciadas.

Bezerra \& Silva (2016, p.01) alegam que "os autores se debruçam a esta temática por entenderem que, de modo geral, é necessário investigar não apenas os embates mercadológicos do turismo, mas também as relações que essa atividade desperta na sociedade". Os estudos voltados às experiências turísticas, em suma, buscam entender as relações estabelecidas entre turista e o destino 
visitado, alguns, debruçam-se a entender como uma experiência se torna memorável. Sun-Tung \& Ritchie (2011, p. 1368), dizem que "apesar do enfoque generalizado e do reconhecimento de estudos sobre experiências memoráveis mais especificações devem ser feitas para se descobrir sobre a experiência, sua essência, do que exatamente faz certas experiências especiais, espetaculares, adequadas e memoráveis".

Trigo (2010) aponta que as viagens proporcionam uma experiência positiva ou negativa. Segundo o autor, a experiência positiva é aquela que supera a banalidade, os aspectos triviais, estereotipados e convencionais, tornando-se marcante. Trata-se de uma experiência enaltecida da riqueza pessoal de quem viaja e busca momentos e lugares que enriqueçam sua história. Contrapartida, caso isso não ocorra, o que restará é uma felicidade dúbia e sentimento de frustração que gera uma incompreensão dos paradoxos e contradições inerentes à viagem e à experiência proporcionada pela mesma.

Chandralal \& Valenzuela (2013) expõem que com o reconhecimento dos destinos turísticos como amalgama do produto turístico, a ênfase passou a ser nas experiências turísticas para que elas sejam únicas, marcantes e memoráveis. Viajar passa a ser a busca de experiências. A experiência passa a ser produto chave do turismo contemporâneo e também de estudos e estudiosos do turismo. Referente aos estudos turísticos, Uriely (2005, p. 04) diz que "os desenvolvimentos descritos no estudo das experiências turísticas estão associados com um desenvolvimento cultural mais amplo, que é referida na literatura como pós-modernista". Para Uriely (2005) a noção pós-moderna referente ao conhecimento acadêmico, é utilizada por aqueles que percebem os recentes desenvolvimentos nas ciências sociais de uma pluralidade cultural, a desconstrução, a subjetividade do indivíduo e sua forma de interpretar a vida. Bauman (1992) já mencionava que a pós-modernidade significava muitas coisas diferentes para muitas pessoas diferentes, em outras palavras, cada lugar e cada destino, são tratados, interpretados e vivenciados de modo diferente. Cada local conduz uma ligação e dá interpretações e experiências subjetivas e diferentes de acordo com quem visita, podendo assim, conduzir experiências memoráveis ou não.

Entender as experiências turísticas é algo complexo, autores ainda levantam questões sobre o estudo das experiências. Sun-Tung \& Ritchie (2011) enfatizam algumas tipologias de estudos voltados à experiência, tais como a experiência de qualidade, a experiência extraordinária, experiência memorável e estudos mais recentes que abarcam a experiência criativa. Coelho et al. (2018) alegam que embora esses termos estejam presentes e sejam relevantes na literatura, eles estão sendo usados sem comum acordo e parecem ter definições intercambiáveis. A questão é que dentre eles, os estudos voltados às experiências memoráveis, construídos a partir da experiência do turista, tem proximidade com a economia da experiência de Pine II \& Gilmore (1998) que influencia estudos no campo do turismo e, portanto, possui maior potencial para explicar as relações entre turismo e experiência.

Deste modo, o objetivo desse estudo é analisar as dimensões da experiência definidas por Pine II \& Gilmore (1999), Oh et al. (2007), e também, apresentara ampliação das dimensões encontradas por Pezzi \& Vianna (2015), de forma a compreender os motivos que levaram os turistas que visitaram Natal, capital do Rio Grande do Norte, no ano de 2017, a considerarem suas experiências memoráveis ou não. 
Este artigo tem como base as dimensões educação, entretenimento, escapismo e estética, desenvolvidas pelos autores Pine II \& Gilmore (1999), memória, desenvolvida pelos autores Oh et al. (2007) e a experiência marcante que se trata da contribuição desse estudo. As dimensões de Pine II \& Gilmore (1999) e Oh et al. (2007) já foram trabalhadas em estudo como o de Pezzi \& Vianna (2015) que se refere às dimensões da experiência de pessoas que visitaram Gramado-RS nos anos de 2010 \& 2011. Em seu estudo, emergem três novas dimensões, que são elas: experiência inédita, segurança e hospitalidade. Essas dimensões surgiram a partir dos resultados advindos do estudo dos pesquisadores que entrevistaram turistas que estiveram em Gramado-RS. Segundo Pezzi \& Vianna (2015), no caso da experiência inédita, foi recorrente entre os pesquisadores que o primeiro impacto que era causado pelo local visitado gerava uma marca inédita que se vinculava no imaginário do visitante. As demais dimensões são elos que já compõem o ciclo turístico: as preocupações com a segurança da localidade visitada e a relação da hospitalidade dos receptores locais durante o processo da viagem.

Por fim, trata-se de um artigo de natureza exploratória e de abordagem quantitativa. Os dados aqui mencionados foram tratados de forma descritiva. Na parte introdutória explanou-se a necessidade de estudos que se voltem a analisar as dimensões da experiência turística, a seguir, é apresentado um levantamento teórico composto pela discussão do turismo e da experiência. É a fundamentação necessária para entender as dimensões para as quais a pesquisa se aprofunda. A terceira parte do artigo apresenta discussões dos procedimentos metodológicos que foram utilizados na pesquisa. A quarta parte menciona os resultados obtidos. A quinta parte trata das considerações finais.

\section{EXPERIÊNCIA TURÍSTICA: DA MEMÓRIA À COMERCIALIZAÇÃo}

A priori, o estudo esclarece que a palavra experiência mencionada nesse artigo faz jus ao estudo de Pezzi \& Vianna (2015), seguido pelo estudo de Turner (1982), que define etimologicamente a experiência como:

Palavra de origem inglesa com uma derivação da base indo-europeia, pertentar, aventurar-se, arriscar... É o cognato germânico de per relacionar experiência com passagem, medo e transporte... 0 grego perão relaciona experiência a "passagem através" com implicações em ritos de passagem. Em grego e latim, experiência associa-se a perigo, pirata e ex-per-imento, Turner (Turner, 1982, p.17).

Tendo como ponto de partida a etimologia da palavra experiência, é perceptível que a mesma expressa pontos que vão além da simples vivência. Trata-se de passagens de ritos que requerem aventurar-se de forma diferente do cotidiano. Mesmo que toda viagem apresente uma experiência, seja positiva ou negativa, nem toda viagem será uma experiência marcante e memorável, conforme mencionam Trigo (2010), e Bezerra \& Silva (2016).

Existe uma dicotomia que distingue a mera experiência de uma experiência única e autêntica. Pine II \& Gilmore (1998) apontam que a experiência surge como principal diferencial em meio à sociedade com práticas turísticas massificadas. Suas teorias na publicação do livro intitulado The Experience Economy (1999), 
argumentam que cada negócio fechado com um cliente precisa ser um evento memorável e que essa memória é o que se configurará como o produto da transação turística. No mesmo ano, Rolf Jensen, surgia com o livro The Dream Society (1999), evidenciando que o turista quer ser o ator de sua própria experiência, isso transgride a ideia de uma sociedade necessitada apenas de informação, mas que busca sonhos e vivenciar os mesmos através de experiências. É a partir daí que a busca de experiências memoráveis se tornaria o ponto primordial das viagens. Tais acontecimentos levaram a colocar a vivencia do turista no ponto central das viagens. As viagens com fins turísticos, quando comercializadas, institucionalmente ou não, passam a ter em sua essência a necessidade à experiência, e ela tornar-se ênfase da atividade turística (Chandralal \& Valenzuela, 2013).

O fato é que a busca da experiência passou a ser vista como a chave do produto turístico atual (Chandralal \& Valenzuela, 2013). Um exemplo é o denominado termo Turismo de Experiência, mesmo nome dado ao livro dos escritores brasileiros Panosso Netto \& Gaeta (2010). Para os autores, a experiência da viagem paradigmática é uma experiência considerada genuína, é algo que transforma as pessoas. No chamado turismo de experiência, o turista se insere no cotidiano do local visitado e realiza tarefas pertencentes à comunidade local. Tendo também a noção dessa experiência como contraria à rotina cotidiana, conforme retrata Mac Cannell (2003).

O Turismo de Experiência, "é o termo mercadologicamente utilizado na atualidade para descrever uma forma de formatar produtos turísticos, inserindo o turista como protagonista de sua própria viagem, (Pezzi \& Vianna, 2015, p. 170)". A inserção do turista com os acontecimentos locais do destino se sobressai e é vendida, comercializada como experiência. Porém, a experiência genuína ultrapassa os valores econômicos e mercadológicos e pode não ser definida pelo ato de atividades nos afazeres locais. Mesmo que alguém visite lugares que tem como foco o turismo rural e se insira no mesmo, plantar e colher, fazer as atividades que os moradores locais fazem não necessariamente será ou se tornará uma experiência memorável.

As empresas vendem o termo experiência como fator chave das viagens. Só o contato com a atividade local, dentre outras formas e atividades distintas relacionadas ao turismo, por si só, não se caracteriza como uma experiência turística memorável, mas o mercado turístico fez com que a experiência adquirisse valor de uso comercial e já não se trata apenas de valores memoráveis. Ao encontro desse posicionamento Bezerra \& Silva (2016, p.06) alegam que "a experiência adquiriu além do valor de troca, no sentido de trocar e adquirir experiências de viagem, o valor de uso, onde passa a ser comercializada e ligada a questões econômicas dentro da atividade turística". Como consequência dessa transformação de valores, a experiência progride como fator econômico da viagem.

0 mercado, não só no setor do turismo, passa a mensurar o valor da experiência como fator de diferenciação de um produto ou serviço. Pine II \& Gilmore $(1999 ; 2000)$ alegam que o único jeito do mercado alcançar as pessoas é proporcionando às mesmas uma experiência. Para tanto, os autores elaboraram a progressão do valor econômico da experiência (Figura 1). Nesse ponto de vista, a experiência encontra-se inserida no mercado, acima dos valores de commodities, bens de consumo e serviços. 
Figura 1 - Análise da Progressão do Valor Econômico da Experiência

relevância para o cliente a preço premium

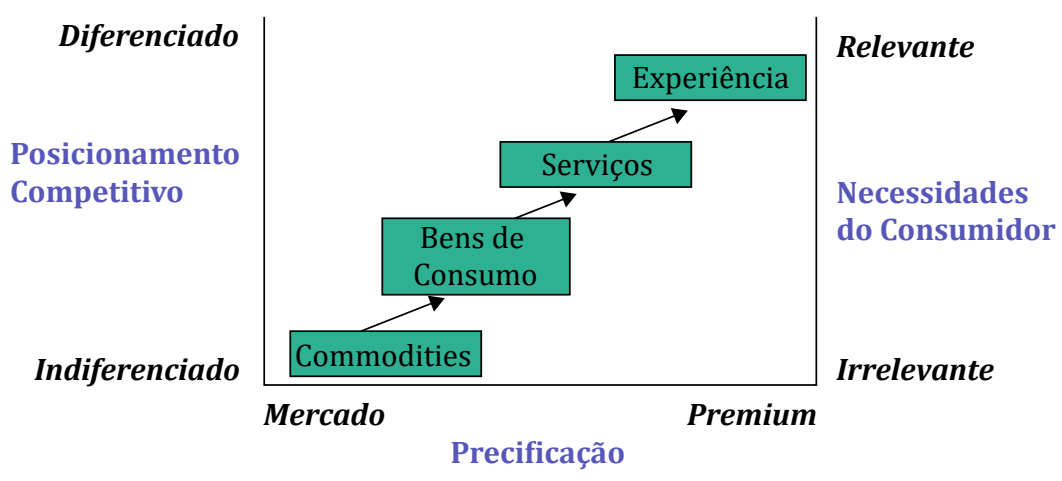

Fonte - Pine II \& Gilmore (1999, p. 22)

A Figura 1 representa uma análise do valor econômico, onde se torna visível que ao longo do tempo foi possível notar mudanças no mercado. No entanto, o marketing de destinos turísticos ainda é impulsionado pela entrega de serviços de qualidade com foco em commodities, ignorando a crente demanda por experiência única e memorável (Chandralal \& Valenzuela, 2015). Beni (2003) diz que na contemporaneidade voltar-se para o mercado turístico de forma competitiva é saber centrar sua competitividade no planejamento e na gestão da experiência. Para Bezerra \& Silva (2016) a Figura 1 tem na experiência o grau mais elevado de diferenciação e relevância para o turista, indo além dos serviços, do bem de consumo e das commodities. Em suma, as relações experienciais dos indivíduos tornaram-se parte do mercado e consequentemente passaram à comercialização.

\section{PROCEDIMENTOS METODOLÓGICOS}

Trata-se de um estudo de natureza quantitativa com questionário estruturado em escala tipo Likert. Tem a finalidade de analisar os fatores que compõem uma viagem considerada memorável para os turistas que visitaram Natal-RN durante o segundo semestre do ano de 2017, julho a dezembro. Aplicou-se o total de 102 questionários que tiveram como base o modelo desenvolvido a partir dos estudos de Pine II \& Gilmore (1999), Oh et al. (2007). A ferramenta de pesquisa se encontra no Apêndice A desse artigo.

Diante das dimensões expostas que compõem essa pesquisa, elaborou-se a Figura 2, que abarca todas as dimensões mencionadas nos estudos anteriores e agrega a dimensão incrementada por esse estudo. Das dimensões presentes na Figura 2, as quatro destacadas de azul fazem referência às dimensões da experiência elaboradas por Pine II \& Gilmore (1999). A quinta dimensão, na cor laranja, faz referência ao estudo de Oh et al. (2007) que propôs a consequência da experiência ser inesquecível quando atrelada à memória. As dimensões na cor verde compõem o campo encontrado no estudo de Pezzi \& Vianna (2015). A dimensão na cor roxa foi adicionada nesse estudo por entender a necessidade de tratar a experiência como fator marcante e só então memorável. 
Figura 2 - Dimensões que compõem a experiência memorável

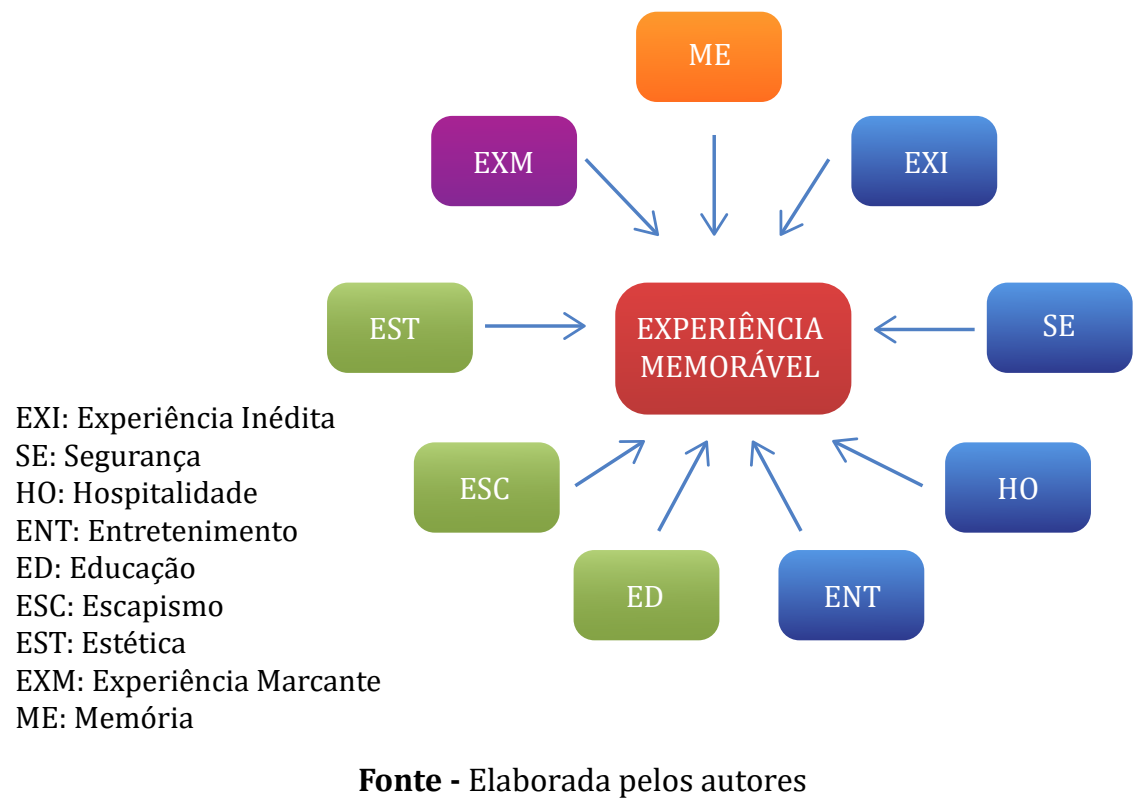

Portanto, esse estudo amplia as dimensões trabalhadas por Pezzi \& Vianna (2015), assim como por seus antecessores, ao adicionar a dimensão experiência dentro do constructo que origina o modelo de questionário já validado pelos estudos anteriores. Antes o modelo possuía 19 questões contando apenas com as dimensões: educação, estética, entretenimento, escapismo e memória, (Pine II \& Gilmore, 1999; Oh et al., 2007). Adicionada a experiência marcante (tratada na Tabela 1 apenas como experiência), o modelo passou a ser composto por 23 questões. As quatro últimas questões que se encontram no apêndice foram as inseridas no modelo.

A pesquisa possui caráter exploratório e foi desenvolvida e analisada através de seis das nove dimensões, sendo essas: o entretenimento, a educação, o escapismo, a estética, a memória e a experiência como fator marcante, dimensão inserida nesse estudo. A inserção dessa dimensão partiu do princípio defendido por Trigo (2010), Bezerra \& Silva (2016), de que toda viagem requer uma experiência, porém, nem todas são marcantes a ponto de serem memoráveis.

A experiência inédita, segurança e hospitalidade encontradas no estudo de Pezzi \& Vianna (2015) não fizeram parte do objeto de pesquisa, questionário, apesar do estudo realizado pelos autores apresentar o surgimento dessas dimensões a partir das entrevistas realizadas com o grupo pesquisado. Os autores apenas identificaram as dimensões, não agregaram estruturalmente essas dimensões no instrumento de pesquisa utilizado na pesquisa, instrumento esse, criado a partir dos estudos de Pine II \& Gilmore (1999), Oh et al. (2007).

Após demarcar a ampliação e as limitações desse estudo, as dimensões da pesquisa e seu instrumento de pesquisa, ocorreu a aplicação dos questionários com os 102 participantes. Em sequência o tratamento estatístico dos dados no software SPSS, foram analisados a média e o desvio padrão de cada questão que compõe as dimensões, conforme Tabela 1. 
Tabela 1 - Dimensões dos constructos da Experiência Memorável

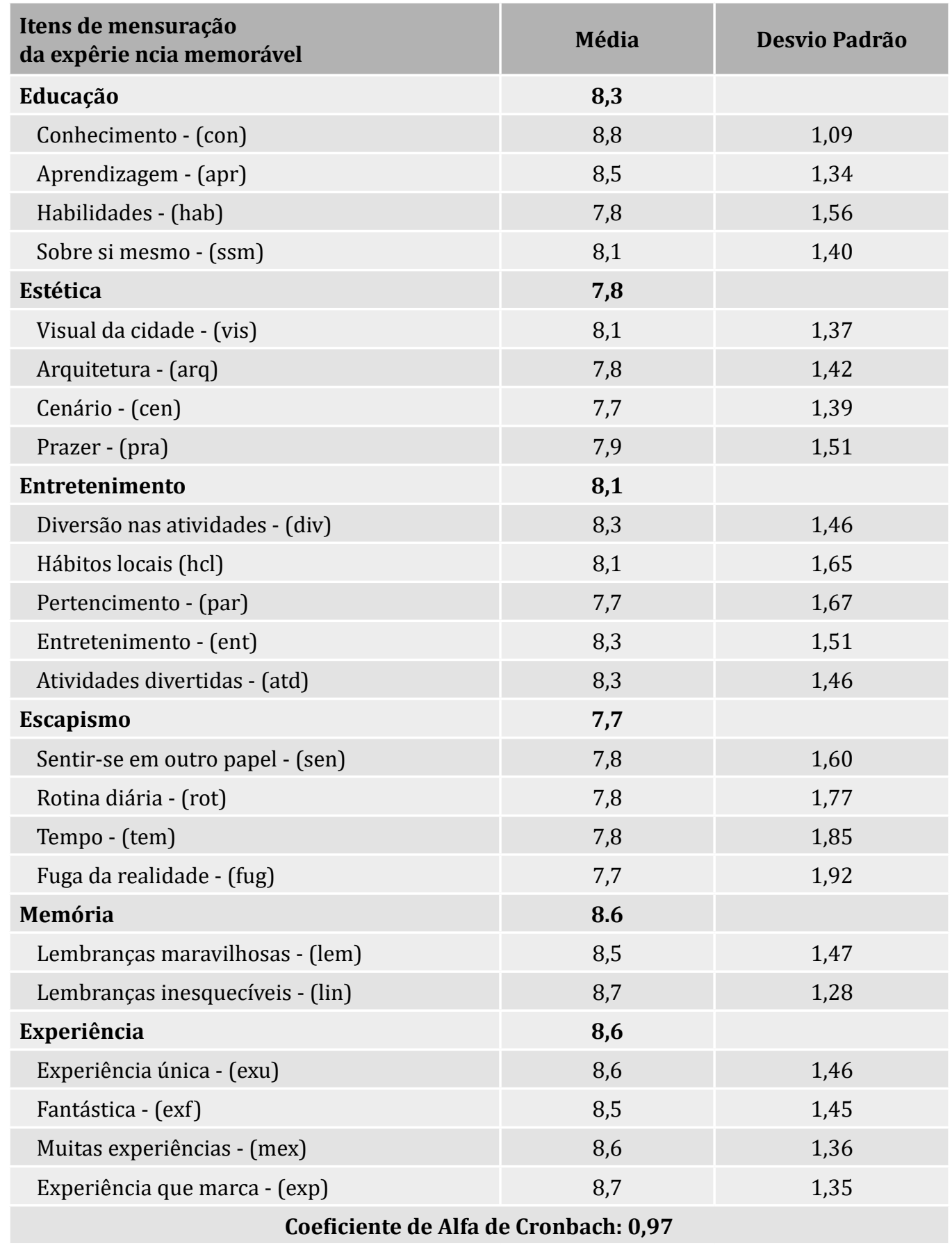

Fonte - Dados da pesquisa, 2017

A Tabela 1 representa a média das respostas obtidas nos 102 questionários e em cada uma das dimensões que foram trabalhadas.

Para finalizar, os dados trabalhados foram analisados de formas correlatas. A correlação foi realizada dentro de cada dimensão com a finalidade de identificar dentre as variáveis existentes quais são as que influenciam o indivíduo a definir o lugar visitado como uma experiência memorável. Além disso, o coeficiente do Alfa de Cronbach do instrumento de pesquisa é de 0,97 e está acima do que menciona Hair Jr, Babin, Samouel \& Money (2005), quando se refere que o limite 
aceitável para as pesquisas das ciências sociais é o alfa acima de 0,70, portanto, o instrumento trabalhado consolida-se fidedigno.

\section{ANÁLISE DE DADOS: RESULTADOS}

Este estudo buscou entender as experiências consideradas memoráveis, permitiu analisar de forma correlata os dados coletados e enfatizar qual a dimensão e quais os fatores que tornaram a cidade memorável. Nesse contexto, o primeiro fato a se destacar na pesquisa é que com a média dos itens de mensuração, expostos na Tabela 2, é possível identificar que, entre as dimensões trabalhadas, uma das que se destaca é a própria experiência com a média de 8,6.

Tabela 2 - Média decrescente das dimensões do constructo

\begin{tabular}{|l|c|}
\hline Dimensões & Média \\
\hline Experiência & 8,6 \\
\hline Memória & 8,6 \\
\hline Educação & 8,3 \\
\hline Entretenimento & 8,1 \\
\hline Estética & 7,8 \\
\hline Escapismo & 7,7 \\
\hline
\end{tabular}

Fonte - Dados da pesquisa, 2017

A Tabela 2 evidencia que as experiências proporcionadas pela cidade, seguida da memória que essas experiências irão deixar nos turistas e/ou viajantes são denominadas como fatores importantes para a experiência ser tida como memorável. Após, segue a importância da experiência e das memórias serem voltadas ao aprendizado, à educação e que sirvam de entretenimento. A estética da cidade também possui sua relevância para os visitantes, a estética é composta pelo visual da cidade, a paisagem, e antes de tudo o turismo também é uma experiência visual. Por fim, o escapismo que se trata da capacidade que a cidade tem em proporcionar uma fuga da realidade, da rotina, do cotidiano do turista/viajante.

Dentre as dimensões trabalhadas o escapismo apresenta a média mais baixa. Sentir-se em outro papel, esquecer-se da rotina diária, perder a noção do tempo durante a viagem a ponto de permitir ao viajante/turista a fuga da realidade, não obteve uma média acima da estética e demais dimensões. É possível inferir que mesmo a viagem sendo propulsora da fuga do cotidiano, como mencionado por Krippendorf (1989), essa fuga por si só não representa uma experiência memorável. Contudo, a dimensão escapismo é tão significativa quanto às demais já que uma viagem memorável deve ter como base as contribuições dessas dimensões. Também é importante lembrar que tal realidade se aplica a Natal-RN, em outras cidades a dimensão escapismo pode apresentar um potencial elevado, maior que o apresentado nesse estudo.

A Tabela 2 apresenta a soma do conjunto de variáveis existentes em cada dimensão e mesmo a dimensão menos avaliada pode apresentar particularidades que enalteçam e componham o elo da experiência memorável. É nesse aspecto que estudos como esse podem ajudar no planejamento e na gestão da experiência, 
tornando o destino mais competitivo, como defendido por Beni (2003). Fatores descobertos por estudos desse porte podem contribuir para melhorar a experiência dos turistas, tornando-a única e memorável, podendo transformar um destino convencional que tem seu marketing impulsionado pelos serviços de qualidade, fincados em commodities, em um destino memorável (Chandralal \& Valenzuela, 2015). Em outras palavras, a capacidade de gerir experiências a partir do que a cidade tem a oferecer pode torná-la memorável.

A Tabela 3 apresenta as dimensões mencionadas e trabalha a correlação de cada item mensurado. Com essa análise foi possível identificar dentro de cada dimensão qual fator é relevante e apresenta grau de intensidade na construção da experiência memorável. Foram utilizados os estudos de Field (2009), Levin (2009), para análise de correlação, eles dizem que quanto mais próximo de um $(1,00)$ em qualquer direção, maior a intensidade de correlação. Os estudos dizem que $+0,80$ ou $-0,80$ possuem intensidade muito forte. Levando essa afirmação em consideração, foram destacadas em cor verde todas as relações consideradas fortes e muito fortes. Para identificar as demais relações seguiu-se a linha de pensamento dos mesmos autores (Field, 2009; Levin, 2009), -1,00 é uma correlação negativa perfeita, $-0,60$ forte, $-0,30$ moderada, $-0,10$ fraca, 0,00 nenhuma correlação, $+0,10$ positiva fraca, $+0,30$ positiva moderada, $+0,60$ positiva forte, $+1,00$ positiva perfeita. Sendo que para as correlações que possuem 0,80 ou mais, sejam essas positivas ou negativas, a cor verde encontra-se na tonalidade escura.

Com base na Tabela 3 de correlação é possível afirmar que, para ter uma experiência considerada memorável é necessário desenvolver aprendizagem de conhecimento do destino que está sendo visitado, conforme a relação de 0,738 entre a variável de conhecimento e aprendizado. Essa é a relação mais forte da dimensão educação e vai ao encontro do que menciona Trigo (2010) quando diz que a experiência é marcante quando apresenta lugares que enriqueçam sua história, ou seja, a cultura do indivíduo, seu grau de aprendizagem.

Quanto à dimensão estética, é perceptível que dentre as variáveis existentes a relação mais forte, a que melhor compõe a experiência considerada memorável ficou entre a arquitetura e o visual da cidade com 0,815 . Novamente, essa relação agrega valor ao impacto que o turismo tem quanto experiência visual. Destaca também que, mesmo a estética sendo a segunda dimensão menos conceituada no conjunto de dimensões, o fator arquitetônico e o fator visual fazem parte do desenvolvimento da experiência memorável.

Dentro da dimensão entretenimento a relação mais forte é composta das atividades realizadas na cidade junto com o entretenimento $(0,809)$ que a mesma oferece. Nesse sentido, afirma-se que quando a vigem proporciona uma relação entre diversão e entretenimento nas atividades realizadas, ela se aproxima de uma experiência considerada memorável.

Quanto à dimensão escapismo, a maior correlação é tempo e rotina. Perder a noção do tempo durante o período de viagem e esquecer-se completamente da rotina durante a viagem são as relações mais conceituadas dentro da dimensão com 0,859. Destaca-se também a relação entre a fuga da realidade com a perda da noção do tempo que apresentam uma correlação de 0,857 . Tais dados levam a afirmar que quando se viaja, perder a noção do tempo e esquecer-se da rotina, do cotidiano, faz com que a viagem se torne marcante, prazerosa e agradável. Consequentemente, a fuga da realidade é o sentido do escapismo. 


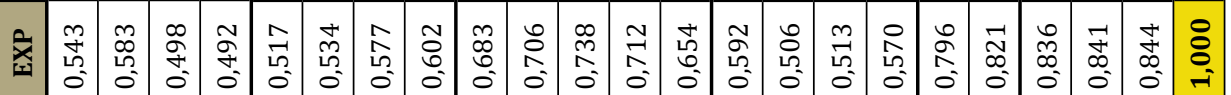

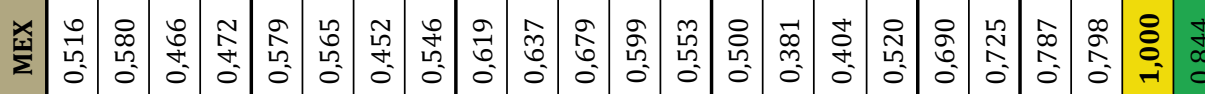

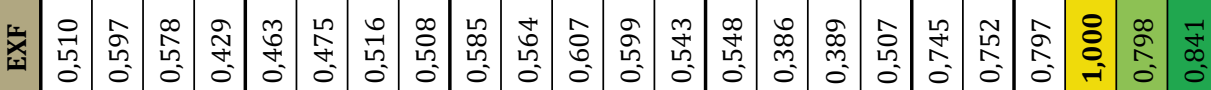

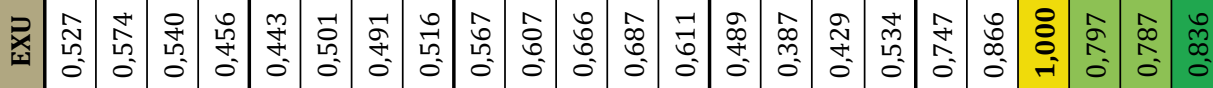

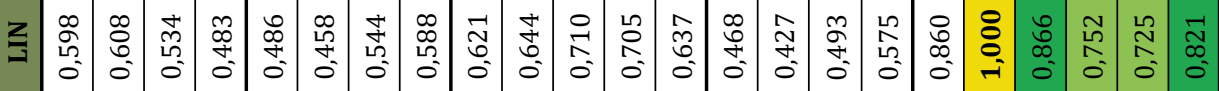

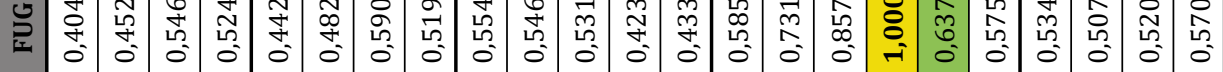

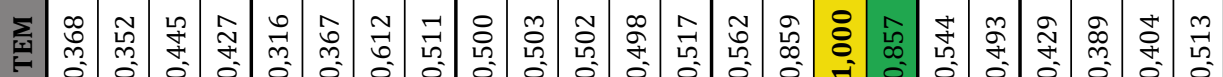

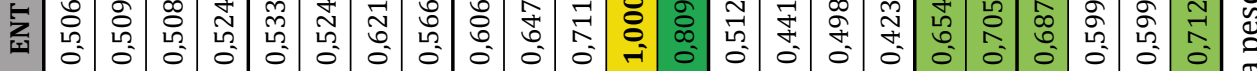

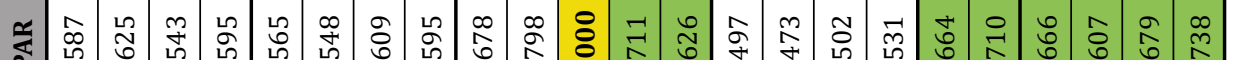

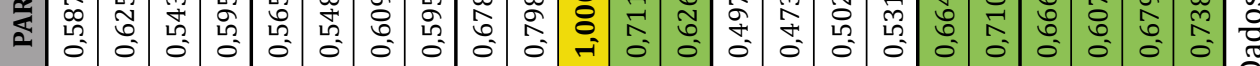

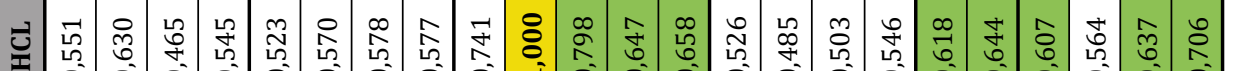

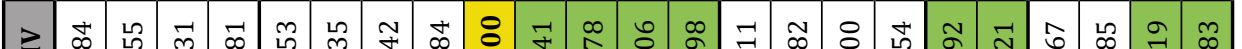

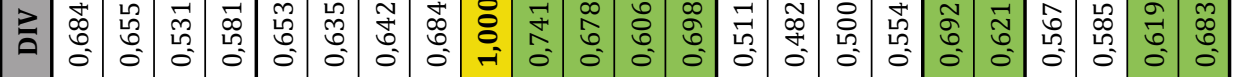

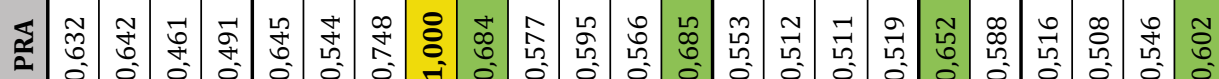

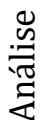

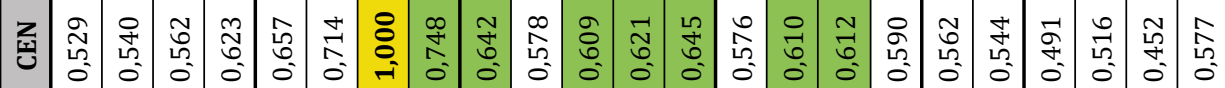

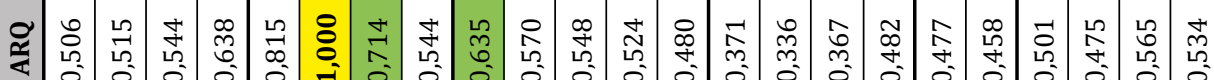
$\frac{\sqrt{\frac{\pi}{2}}}{\frac{\pi}{4}}$

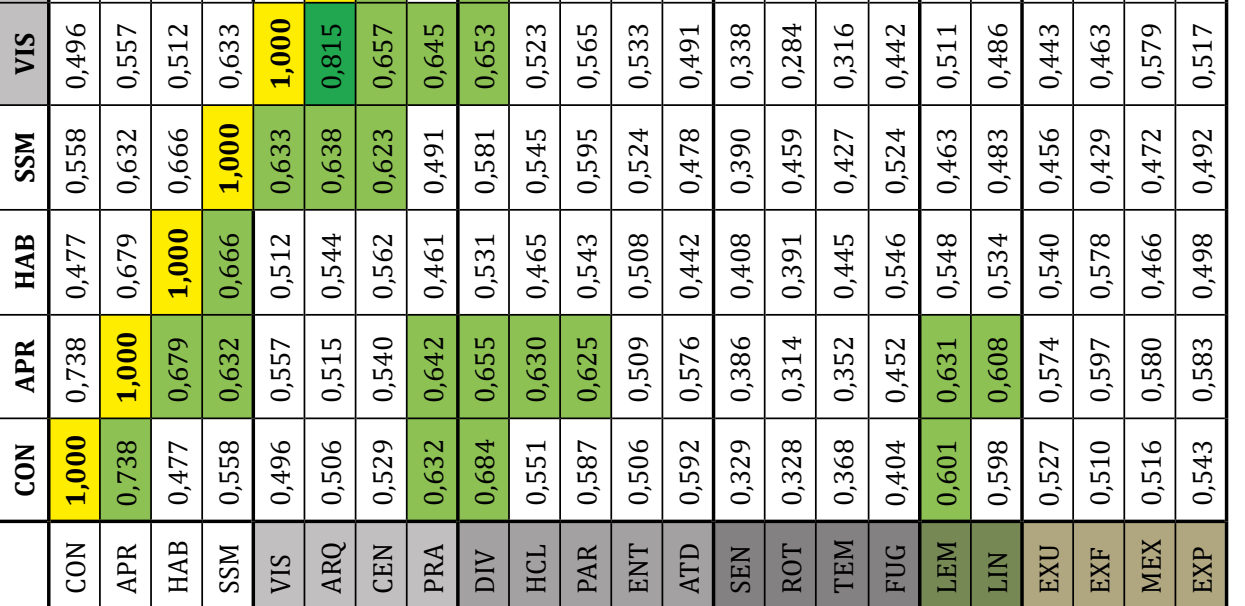


A experiência do turismo possui em sua construção uma fuga daquilo que se faz presente no cotidiano. Faz parte do ciclo de reconstituição característico da sociedade industrial, a relação entre trabalho-moradia-lazer (Krippendorf, 1989). Isso ocorre como aporte a reconstituição das energias para voltar à rotina. É possível perceber que da dimensão escapismo é essencial à quebra da rotina, esquecer-se do tempo, e que mesmo a fuga sendo similar ao local em que se vive, ela possui a capacidade de gerar lembranças. São essas lembranças que se fixam na memória, permitem lembrar-se da cidade e buscar experiências similares.

A dimensão memória, que é a única composta de duas variáveis, apresentou uma correlação de 0,860 que se refere à questão de nunca esquecer as experiências vividas em Natal-RN. Trata-se da dimensão que envolve lembrar-se da cidade. Não meras lembranças, mas lembranças maravilhosas que permitiram confirmar a relação entre viagem e memória marcante. É a memória composta por lembranças que as pessoas tiveram da cidade e que lhes conduzirão a indicar para outros turistas e viajantes. São essas lembranças que podem conduzir o retorno do turista à cidade visitada.

A última dimensão analisada, a experiência, constatou que para os visitantes de Natal-RN a experiência obtida na cidade foi positiva e marcante. Isso ocorre porque Natal-RN é uma cidade onde se pode viver muitas experiências. Essa afirmação parte da correlação entre experiências positivas e marcantes com o local onde se pode obter muitas experiências, juntas as variáveis obtiveram uma correlação equivalente a 0,844 .

A dimensão experiência foi uma das mais bem-conceituadas, tendo obtido a mesma média da dimensão memória $(8,6)$, a experiência se destaca por possuir quatro variáveis que obtiveram correlações acima de 0,80 caracterizando suas ligações como muito forte (Field, 2009), (Levin, 2009). As demais variáveis que compõem a dimensão eram experiências obtidas na cidade como fantásticas, e como experiência única, tiveram uma correlação com a questão de a Cidade de Natal-RN ser parte de uma experiência positiva e marcante, obtiveram respectivamente 0,841 e 0,836 .

Um fator de destaque presente nas variáveis foi a correlação entre uma variável do campo experiência (EXU) e outra do campo memória (LIN), juntas obtiveram uma correlação de 0,866, a maior correlação. Essas variáveis enfatizam que estar em Natal-RN foi uma experiência única e que consequentemente os visitantes, turistas, não irão se esquecer das experiências obtidas na cidade. Esse fator complementa ainda mais a busca por descobrir a relação das experiências consideradas memoráveis.

Com base em todas as variáveis mensuradas, é possível destacar um ponto forte existente em cada dimensão, esses fatores são considerados por esse estudo como os elos que compõem a experiência denominada memorável pelos turistas. Para a composição desses fatores levou-se em consideração a força de correlação existente entre as variáveis, destacando a maior correlação entre cada dimensão, salvo a dimensão escapismo por entender que o esquecimento da rotina e a fuga da rotina são questões diferentes, onde no primeiro caso é algo casual enquanto a fuga, nesse caso, é opcional. Assim, o Quadro 1 apresenta os fatores que permitiram considerar Natal-RN uma experiência memorável e teve na dimensão escapismo a seleção de dois fatores. 
Quadro 1 - Conjunto de fatores que tornaram Natal-RN uma experiência memorável

\begin{tabular}{|c|c|c|c|}
\hline Dimensão & Variáveis & Correlação & $\begin{array}{l}\text { Fatores que contribuem para uma } \\
\text { experiência turística memorável }\end{array}$ \\
\hline Educação & $\mathrm{APR}+\mathrm{CON}$ & 0,738 & $\begin{array}{l}\text { O desenvolvimento de aprendizagem e } \\
\text { conhecimento individual sobre a cidade } \\
\text { ou sobre si mesmo durante o seu período } \\
\text { de permanência na cidade; }\end{array}$ \\
\hline Estética & $A R Q+V I S$ & 0,815 & $\begin{array}{l}\text { O conjunto arquitetônico da cidade } \\
\text { e o seu visual serem atraentes; }\end{array}$ \\
\hline Entretenimento & ATD + ENT & 0,809 & $\begin{array}{l}\text { A capacidade da cidade de entreter } \\
\text { a partir de diversas atividades; }\end{array}$ \\
\hline \multirow[b]{2}{*}{ Escapismo } & TEM + ROT & 0,859 & $\begin{array}{l}\text { A viagem como fator de } \\
\text { esquecimento do tempo e da rotina; }\end{array}$ \\
\hline & FUG + TEM & 0,857 & $\begin{array}{l}\text { A viagem como propulsora da fuga da } \\
\text { realidade e da noção do tempo durante } \\
\text { a realização das atividades locais; }\end{array}$ \\
\hline Memória & LIN + LEM & 0,860 & $\begin{array}{l}\text { A relação entre memória e indivíduo, } \\
\text { permitindo vivencias consideradas } \\
\text { únicas que acarretam em lembranças } \\
\text { positivas da cidade; }\end{array}$ \\
\hline Experiência & EXP + MEX & 0,844 & $\begin{array}{l}\text { A cidade como propulsora de muitas } \\
\text { experiências para seus visitantes. }\end{array}$ \\
\hline
\end{tabular}

Fonte - Dados da pesquisa, 2017

É importante ressaltar que todos os elementos compõem um grau de importância na construção memorável do lugar com o indivíduo e vice-versa, contudo, dentre as variáveis trabalhadas, essas foram as que obtiveram destaque e que ajudaram aos visitantes compor uma imagem do destino Natal-RN em suas memórias.

\section{CONSIDERAÇÕES FINAIS}

Esse estudo teve a finalidade de ampliar as discussões a respeito do turismo e das experiências advindas dessa atividade, em particular, da experiência considerada memorável. Entende-se aqui a necessidade de galgar caminhos que levem a entender as relações que estão além dos fatores mercadológicos da área do turismo, e assim, traçar caminhos para consolidar o entendimento das experiências memoráveis diante de tantos estudos que abordam a relação das experiências do turista.

Com base nas discussões sobre turismo, memória e experiência foi possível averiguar que as relações econômicas e de marketing passaram a comercializar a experiência, mas essa pesquisa mostrou que uma experiência autêntica e marcante, a ponto de ser memorável, requer um conjunto de variáveis que vão além dos fatores mercadológicos.

A experiência considerada memorável trata-se de um conjunto que leva em consideração o aprendizado sobre o lugar, seus aspectos visuais, o entretenimento existente na cidade, a capacidade que a cidade tem para com o indivíduo, permitindo o mesmo fugir e esquecer-se do seu cotidiano, a capacidade do lugar se 
fazer memorável e presente em suas lembranças e, por fim, a possibilidade de proporcionar diferentes experiências de diferentes formas.

Mesmo tendo como base os visitantes que estiveram em Natal-RN, os resultados obtidos não se configuram como padrão, tais variáveis podem apresentar resultados distintos de acordo com o destino ao qual o instrumento de pesquisa desse estudo é aplicado. Contudo, as variáveis e as dimensões estudadas nessa pesquisa apresentam relações plausíveis e vão ao encontro da literatura sobre turismo e experiência memorável.

Conclui-se que tal estudo contribui diretamente com a experiência memorável do turismo, e deixa claro que a busca por novas dimensões, pela ampliação do instrumento da coleta de dados desse estudo, e por destinos distintos dos já trabalhados, como Gramado-RS e Natal-RN, são pesquisas que ampliariam o conhecimento sobre a temática.

A construção de estudos que se voltem à epistemologia da experiência memorável do turismo também se caracteriza como ampliação, assim como estudos que analisem as nove dimensões encontradas nessa pesquisa, já que o mesmo se voltou a trabalhar apenas seis delas. Isso permite reflexões profundas a respeito dessa temática, pois se acredita que apenas por meios de reflexões sobre esse aporte teórico é que se poderá compreender com clareza e fazer mais a respeito das relações entre turismo, experiência e memória.

\section{REFERÊNCIAS}

Bauman, Z. (1992). Intimations of Postmodernity. London: Routledge.

Beni, M. C. (2003). Globalização do turismo: megatendências do setor e a realidade brasileira. São Paulo: Aleph.

Bezerra, L. T., \& Silva, F. F. (2016). A construção da experiência turística por intermédio da imagem e do imaginário do viajante. Anais do Seminário da ANPTUR.

Coelho, M. de F., Gosling, M de S., \& Almeida, A. S, A. (2018). Tourism experiences: Core processes of memorable trips. Journal of Hospitality and Tourism Management. V.37, pp 11-22.

Chandralal, L., \& Valenzuela, F. R. (2013). Exploring memorable tourism experiences: antecedentes and behavioural outcomes. Journal of Economics, Business and Management, vol. 1, n. 2, pp. 177-181.

Chandralal, L., \& Valenzuela, F. R. (2015). Memorable Tourism Experiences: Scale Development. Contemporary Management Research. vol. 11, n. 3, pp. 291-310,

Dawsey, J. C. (2005). Victor Turner e antropologia da experiência. Caderno de campo, São Paulo, n. 13, pp. 163-176.

Field, A. P. (2009). Descobrindo a estatística usando o SPSS. 2 ed. Porto Alegre: Artmed.

Hair Jr., J. F., Babin, B., Samouel, P., \& Money, A. (2005). Fundamentos de métodos de pesquisa em administração.Porto Alegre: Bookman.

Jensen, R. (1999). The dream Society: How the coming shift from information to imagination will transform your business. New York: McGraw-Hill.

Kim, J. (2009). Development of a scale to measure memorable tourism experiences. Unpublished doctoral thesis, Indiana University, Bloomington. 
Krippendorf, J. (1989). Sociologia do Turismo: para uma nova compreensão do lazer e das viagens. Rio de Janeiro: Civilização Brasileira,

Levin, J. (2009). Estatística para ciências humanas. 11 ed. São Paulo: Person.

Li, Y. (2000). Geographical consciousness and tourism experience. Annals of Tourism Research, vol.27, n. 4, pp. 863-883.

Mac Cannell, D. (2003). El Turista, uma nueva teoria de la clase ociosa.Barcelona: Ed. Melusina.

Oh, H., Fiore, A. M., \& Jeoung, M. (2007). Measuring experience economy concepts: tourism applications. Journal of Travel Research, n. 46, p. 119-32, Nov.

Panosso Netto, A., \& Gaeta, C. (2010). Turismo de Experiência. São Paulo: SENAC.

Pezzi, E. \& Vianna, S. L. G. A. (2015). Experiência Turística e o Turismo de Experiência: um estudo sobre as dimensões da experiência memorável. Turismo em Análise. Vol. 26, n. 01.

Pine II, B. J.; \& Gilmore, J. H. (1999). The experience economy: work is theatre and every business a stage. Boston: Harvard Business School Press.

Pine II, B. J.; \& Gilmore, J. H. (1999). The Experience Economy. Boston: Harvard Business School Press.

Pine II, B. J.; \& Gilmore, J. H. (2000). Gilmore, J. H. Welcome to the experience economy. Harvard Business Review, 76, (4), 1998, pp.97-105.

Sun-Tung, V. W., \& Ritchie, J. R. B. (2011). Exploring the essence memorable tourism experiences. Annals of Tourism Research, Vol. 41, pp. 153-174

Trigo, L. G. G. (2010). A viagem como experiência significativa. In: TRIGO, L. G. G. Turismo de Experiência. São Paulo: SENAC, 2010. p. 21-42

Turner, V. W. (1982). From ritual to theatre. New York: Performing Arts Journal Press.

Turner, V. W. Dewey. (1986). Dilthey and Drama: an essay in the anthropology of experience In: Turner, V. W.; Bruner, E. M. (Eds.). Anthropology of Experience. Urbana and Chicago: University of Illinois Press, pp. 33-44.

Uriely, N. (2005). The tourist experience, conceptual developments. Annals of Tourism Research. Vol. 32, n. 1, pp. 199-216.

\section{CONTRIBUIÇÃo}

Leandro Tavares Bezerra: Autoria única. 


\section{APÊNDICE}

Gostaria de contar com a sua colaboração para responder essa pesquisa. Visa compreender os elementos que definem as experiências turísticas. Ressalvo a garantia da privacidade de seus dados pessoais. Essas informações não serão divulgadas a terceiros. As respostas devem estar relacionadas com as experiências da sua viagem a Natal.

Por favor, indique seu grau de concordância com as afirmações a seguir. A escala varia de 0 (zero) quando discordar totalmente da afirmação até 10 (dez) quando concordar totalmente com a afirmação. Assim, por favor, marque a opção que mais condiz com as experiências obtidas em

\begin{tabular}{|c|c|c|c|c|c|c|c|c|c|c|c|c|}
\hline Código & Afirmação & \multicolumn{6}{|c|}{$\begin{array}{l}\text { Discordo } \\
\text { totalmente }\end{array}$} & \multicolumn{5}{|c|}{$\begin{array}{l}\text { Concordo } \\
\text { Totalmente }\end{array}$} \\
\hline $\mathrm{COM}$ & $\begin{array}{l}\text { A viagem à Natal me proporcionou } \\
\text { novos conhecimentos }\end{array}$ & 0 & 1 & 2 & 3 & 4 & 5 & 6 & 7 & 8 & 9 & 10 \\
\hline APR & $\begin{array}{l}\text { A viagem à Natal estimulou minha curiosidade para } \\
\text { aprender coisas novas }\end{array}$ & 0 & 1 & 2 & 3 & 4 & 5 & 6 & 7 & 8 & 9 & 10 \\
\hline HAB & $\begin{array}{l}\text { A experiência melhorou minha } \\
\text { habilidade cognitiva e/ou física }\end{array}$ & 0 & 1 & 2 & 3 & 4 & 5 & 6 & 7 & 8 & 9 & 10 \\
\hline SSM & $\begin{array}{l}\text { Essa experiência fez com que eu } \\
\text { aprendesse mais sobre mim mesmo }\end{array}$ & 0 & 1 & 2 & 3 & 4 & 5 & 6 & 7 & 8 & 9 & 10 \\
\hline VIS & O visual da cidade é bastante atraente & 0 & 1 & 2 & 3 & 4 & 5 & 6 & 7 & 8 & 9 & 10 \\
\hline ARQ & A arquitetura do local despertou meu interesse & 0 & 1 & 2 & 3 & 4 & 5 & 6 & 7 & 8 & 9 & 10 \\
\hline CEN & O cenário da cidade é harmonioso & 0 & 1 & 2 & 3 & 4 & 5 & 6 & 7 & 8 & 9 & 10 \\
\hline PRA & O fato de estar em Natal por si só foi muito prazeroso & 0 & 1 & 2 & 3 & 4 & 5 & 6 & 7 & 8 & 9 & 10 \\
\hline DIV & As atividades que participei foram divertidas & 0 & 1 & 2 & 3 & 4 & 5 & 6 & 7 & 8 & 9 & 10 \\
\hline HCL & Eu gostei de conhecer os habitantes da comunidade local & 0 & 1 & 2 & 3 & 4 & 5 & 6 & 7 & 8 & 9 & 10 \\
\hline PAR & $\begin{array}{l}\text { Eu me senti parte da comunidade } \\
\text { durante as atividades que participei }\end{array}$ & 0 & 1 & 2 & 3 & 4 & 5 & 6 & 7 & 8 & 9 & 10 \\
\hline ENT & As atividades vividas na viagem me entretiveram & 0 & 1 & 2 & 3 & 4 & 5 & 6 & 7 & 8 & 9 & 10 \\
\hline ATD & As atividades na viagem foram divertidas & 0 & 1 & 2 & 3 & 4 & 5 & 6 & 7 & 8 & 9 & 10 \\
\hline SEM & $\begin{array}{l}\text { A experiência durante a viagem permitiu } \\
\text { que eu me sentisse em outro papel }\end{array}$ & 0 & 1 & 2 & 3 & 4 & 5 & 6 & 7 & 8 & 9 & 10 \\
\hline ROT & $\begin{array}{l}\text { Enquanto estive no destino esqueci } \\
\text { completamente a minha rotina diária }\end{array}$ & 0 & 1 & 2 & 3 & 4 & 5 & 6 & 7 & 8 & 9 & 10 \\
\hline TEM & Eu perdi a noção do tempo durante a viagem & 0 & 1 & 2 & 3 & 4 & 5 & 6 & 7 & 8 & 9 & 10 \\
\hline FUG & Eu fugi completamente da realidade & 0 & 1 & 2 & 3 & 4 & 5 & 6 & 7 & 8 & 9 & 10 \\
\hline LEM & Eu ainda terei lembranças maravilhosas dessa viagem & 0 & 1 & 2 & 3 & 4 & 5 & 6 & 7 & 8 & 9 & 10 \\
\hline LIN & Eu nunca vou esquecer a experiência vivida nessa viagem & 0 & 1 & 2 & 3 & 4 & 5 & 6 & 7 & 8 & 9 & 10 \\
\hline EXU & Essa viagem foi uma experiência única & 0 & 1 & 2 & 3 & 4 & 5 & 6 & 7 & 8 & 9 & 10 \\
\hline EXF & A experiência de conhecer Natal foi fantástica & 0 & 1 & 2 & 3 & 4 & 5 & 6 & 7 & 8 & 9 & 10 \\
\hline MEX & Natal é uma cidade onde se pode viver muitas experiências & 0 & 1 & 2 & 3 & 4 & 5 & 6 & 7 & 8 & 9 & 10 \\
\hline EXP & Estar em Natal foi uma experiência positiva e marcante & 0 & 1 & 2 & 3 & 4 & 5 & 6 & 7 & 8 & 9 & 10 \\
\hline
\end{tabular}

